\title{
Adult African Americans undergoing cadaveric liver transplantation for hepatocellular carcinoma within the Milan criteria have the lowest 5-year survival among all the ethnic groups in the United States: analysis of USA national data between January 2002 and June 2013
}

\author{
Michele Molinari', Subhashini Ayloo ${ }^{2}$, Allan Tsung ${ }^{1}$, Patrick Bou Samra ${ }^{1}$, Naudia Jonaissaint ${ }^{3}$ \\ 'Department of Surgery, University of Pittsburgh Medical Center, Pittsburgh, PA 15213, USA. \\ 2Department of Surgery, Rutgers New Jersey Medical School, Newark, NJ 07103, USA. \\ ${ }^{3}$ Department of Medicine, University of Pittsburgh Medical Center, Pittsburgh, PA 15213, USA.
}

Correspondence to: Prof. Michele Molinari, Division of Transplantation, University of Pittsburgh Medical Center, 3459 Fifth Avenue, N758, Pittsburgh, PA 15213, USA. E-mail: molinarim@upmc.edu

\begin{abstract}
How to cite this article: Molinari M, Ayloo S, Tsung A, Bou Samra P, Jonaissaint N. Adult African Americans undergoing cadaveric liver transplantation for hepatocellular carcinoma within the Milan criteria have the lowest 5-year survival among all the ethnic groups in the United States: analysis of USA national data between January 2002 and June 2013. Hepatoma Res 2018;4:56.
\end{abstract}

http://dx.doi.org/10.20517/2394-5079.2018.71

Received: 1 Jun 2018 First Decision: 23 Jul 2018 Revised: 7 Aug 2018 Accepted: 10 Aug 2018 Published: 20 Sep 2018

Science Editor: Guang-Wen Cao Copy Editor: Cai-Hong Wang Production Editor: Huan-Liang Wu

\begin{abstract}
Aim: To investigate the potential effects of recipient ethnicity on the short and long-term outcomes of patients undergoing liver transplantation (LT) for hepatocellular carcinoma (HCC) in the United States. We performed a retrospective study using the standard transplant analysis and research (STAR) files with the primary aim of assessing short and long-term survival of different ethnic groups undergoing LT for HCC in the United States.
\end{abstract}

Methods: The study population was represented by adults (age $\geq 18$ ) who received a first-time cadaveric LT for HCC between 1 Jan 2002 and 30 Jun 2013. Recipients of LT for other primary and secondary malignancies were excluded. Other exclusion criteria were: transplants from grafts recovered from living or donors after cardiac death, split grafts, multi-visceral or redo transplants, and LT performed across ABO incompatible blood groups. Survival analysis stratified by recipient ethnicity was performed using the Kaplan-Meier method. Proportional hazard model analysis was used to assess the effect of predictors of survival. Characteristics utilized in the Cox regression model were selected a priori.

Results: The study population was represented by 6048 recipients with an average age of 58 years and $20 \%$ being females. The majority of patients were Caucasians (67\%), followed by Hispanics (14.2\%), African Americans 
(8.8\%) and Asians (8.6\%). Overall 30-, 60-, 90-day and 1-year mortality was 1.7\%, 2.3\%, 3.0\% and 8.8\% respectively with no statistically significant differences among ethnicities. Log-rank comparisons however showed that African American had the lowest 5-year survival with statistically significant differences in comparison to all other ethnic groups $(P \leq 0.001)$. At multivariate Cox-regression analysis, African American ethnicity remained an independent predictor for increased mortality (HR $=1.524 ; 95 \% \mathrm{Cl}: 1.283-1.803 ; P<0.001)$ after adjusting for the recipient and donor age, recipient sex, recipient history of diabetes and recipient functional status at the time of transplantation.

Conclusion: Short-term outcomes of African Americans undergoing cadaveric LT for HCC are similar to other ethnic groups. However, African American ethnicity is an independent predictor of lower 5-year overall survival when compared to all other ethnic groups.

Keywords: Hepatocellular carcinoma, ethnicity, survival, Cox-regression, liver transplantation, predictor

\section{INTRODUCTION}

Hepatocellular carcinoma (HCC) is the fifth most common cancer in the world ${ }^{[1]}$ with over 1,000,000 new patients diagnosed every year and 250,000 cancer-related deaths ${ }^{[2]}$. The worldwide incidence of HCC is unequally distributed with South-East Asia and Sub-Saharan Africa having the highest incidence while the lowest is recorded in Western Europe and North America ${ }^{[3]}$. Geographical differences of the incidence of HCC reflect variations of the most common risk factors for HCC such as viral hepatitis B (HBV) and C $(\mathrm{HCV})$, aflatoxin, alcohol consumption and genetics ${ }^{[3,4]}$. However, over the last decades, the incidence of HCC has steadily increased in Western countries due to a rise in the incidence of HCV and non-alcoholic steatohepatitis $(\mathrm{NASH})^{[5]}$.

Treatment modalities for HCC depend on patient age and comorbidities, tumor characteristics and degree of liver disease and portal hypertension in addition to other factors such as local expertise and resources ${ }^{[6]}$. Liver resection and transplantation provide the best long-term survival ${ }^{[7-9]}$ followed by ablative therapies, locoregional and systemic chemotherapy ${ }^{[7,8,10,11]}$. Despite the survival advantage of hepatic resection and liver transplantation (LT), most patients are unable to undergo surgery because of their advanced tumors or the presence of co-morbidities. Even after radical resections, cirrhosis predisposes to the development of recurrent disease in $50 \%-80 \%$ of patients within 5 years ${ }^{[12,13]}$. Consequently, LT remains the best treatment as it addresses both the tumor and cirrhosis ${ }^{[14,15]}$. Nevertheless, only $10 \%-12 \%$ of patients with HCC are transplanted due to the limited number of donors ${ }^{[16-22]}$.

Previous studies have reported that in the United States, LT for HCC is performed less frequently in nonCaucasians than in recipients of other ethnicities ${ }^{[23-25]}$. The reasons for these disparities are not completely understood but there is some evidence suggesting that disadvantaged ethnic groups face more barriers to access healthcare and are more frequently diagnosed with advanced diseases ${ }^{[23,24,26]}$.

To be listed for a LT in the United States and Europe, patients with HCC must fulfill not only strict oncological criteria ${ }^{[15]}$ but also other requirements such as evidence of adequate social support, financial stability, the absence of active mental disorders, abstinence from substance abuse and adherence to diagnostic and therapeutic recommendations. These requirements, especially the ones linked to financial status, might affect certain demographic or socioeconomic groups more than others ${ }^{[27]}$, but are necessary to optimize the outcomes of LT recipients.

Since all LT candidates have to satisfy similar inclusion criteria, we hypothesized that there should not be differences in short and long-term outcomes among different ethnic groups, and since studies on ethnicity 
and outcomes of patients undergoing LT for HCC in the United States are lacking, the primary aim of this study was to assess if African American had short- and long-term outcomes similar to recipients of other ethnic groups.

\section{METHODS}

\section{Study design}

The United network for organ sharing (UNOS) standard transplant analysis and research (STAR) files were used to identify a retrospective cohort of patients who underwent LT for HCC in the United States between 1 Jan 2002 and 30 Jun 2013. The study was conducted and reported per recommendations from STROBE statement ${ }^{[28,29]}$ and did not require approval by the ethics review board of our institution.

\section{Rationale and aims of the study}

There has been some controversy regarding the possible reasons why some ethnic groups have inferior survival than Caucasian recipients after $\mathrm{LT}^{[30-32]}$. Nair et al. ${ }^{[33]}$ have previously reported that being African American or Asian American were risk factors for inferior long-term outcomes after LT. On the other hand, Lee et al.$^{[34]}$ did not find any association between race and post-LT outcomes after adjusting for age, gender, total bilirubin, creatinine and prothrombin time. In more recent years, Wong et al. ${ }^{[30]}$ analyzed the 20022012 STAR files and concluded that African Americans had significantly lower survival compared with nonHispanic whites affected by HCV, alcoholic liver disease, and HCC after adjusting for several demographic and clinical characteristics. To the best of our knowledge this was the only study that assessed the outcomes of LT recipients stratified by their ethnicity after the MELD score was introduced in the USA for the allocation of liver grafts. Although this study had the advantage of including a large number of patients, it was limited by the fact that several predictors of long-term survival were not included in the final Coxregression analysis, and that the study was not specifically designed for patients with HCC. Because of these limitations, we performed a retrospective analysis of the STAR files with the primary aim of testing the null hypothesis, that there were no significant differences in the overall survival of patients with documented HCC and who belonged to different ethnic groups.

\section{Inclusion and exclusion criteria}

All adults (age $\geq 18$ years) undergoing LT for HCC were candidates for this study. No restriction of race, citizenship or UNOS region were applied. Recipients of LT for other primary and secondary malignancies (e.g., cholangiocarcinoma, hepatoblastoma, hemangiosarcoma, neuroendocrine metastasis) were excluded. Other exclusion criteria were: transplants from grafts recovered from living or donors after cardiac death, split grafts, multi-visceral or redo transplants, and LT performed across ABO incompatible blood groups. Additional exclusion criteria were lack of records on short and long-term outcomes, the absence of HCC in the explanted liver or the presence of variables with values that were deemed implausible for adult recipients or for deceased donor LTs ${ }^{[35]}$. Cutoffs for those values were: recipient height either $\leq 120 \mathrm{~cm}$ or $\geq 240 \mathrm{~cm}$, cold ischemia time $\geq 24 \mathrm{~h}$. No imputations of missing data were performed, and recipients who had more than $10 \%$ of unreported values were excluded.

\section{Variables and outcomes}

Variable collected for LT recipients were age at the time of transplant, sex, donor and recipient body mass index (BMI), ethnicity, presence of renal failure requiring hemodialysis before surgery, history of diabetes (either type I or II), mortality within 30-, 60-, 90-day and 1 year after surgery, main cause of death, date of death or date of last follow up, cold ischemia time (h), UNOS region where patients were transplanted. Additional variables collected for the donors were age, sex, height and weight or BMI.

Recipient overall survival was estimated by the difference between the date of transplantation and the date of death from any cause using the Kaplan-Meier method. Censoring was used for recipients who were still alive 
on 30 Jun 2013, or who were alive at the time of the last follow-up or if they underwent re-transplantation (date of redo LT surgery).

\section{Covariates used for Cox regression analysis}

The presence of renal failure requiring hemodialysis prior to LT and history of diabetes (type 1 or type 2 diabetes) were used as 2-level categorical variables (absent or present). Ethnicity was categorized into five groups: Caucasian, African American, Hispanic, Asian and Multiracial including other minorities such as Hawaiian or Native American. The time on the wait list was calculated from the day of listing for LT to the date of surgery irrespective of the length of time that the patient spent in an inactive state. The waiting time was then categorized into four periods: less than 3 months, 3.1-6 months, 6.1-12 months and longer than 1 year. Recipient functional status at the time of LT was measured using the UNOS classification based on the validated Karnowski performance status ${ }^{[36-38]}$. Recipient functional status was reported in the STAR files in $10 \%$ increments with $10 \%$ representing a patient who was moribund to $100 \%$ who represented a fully active and normal individual without complaints and no evidence of disease. Patient functional status was used as a two-level categorical variable: less than $60 \%$ and $60 \%$ or higher. Recipient educational level was stratified into six categories: elementary or middle school (grade 1-8), high school (grade 9-12), college or technical school, associate or bachelor degree, post college or graduate degree. BMI was estimated using the World Health Organization (WHO) formula: weight $(\mathrm{kg}) /$ height $\left(\mathrm{m}^{2}\right)$. The WHO definition of overweight and obesity were used to classify recipients and donors in three categories: normal weight (BMI 18.5-24.9 kg/m ${ }^{2}$ ), overweight (BMI $\left.25-29.9 \mathrm{~kg} / \mathrm{m}^{2}\right)$, obese $\left(B M I \geq 30 \mathrm{~kg} / \mathrm{m}^{2}\right)$. Obesity was further classified as class I (BMI 30-34.9), class II (BMI 35-39.9) and class III (BMI $\geq 40$ ). Data for different BMI classes were not adjusted for the presence of ascites as the quantitative contribution of this to the patients' BMI was not reported in the STAR files.

\section{Statistical analysis}

The sample size of patients was fixed due to the retrospective design of this study. Continuous variables were reported by estimates of central tendency (means or median) and spread [standard deviation and interquartile range (IQR)] while frequency and percentages were used for categorical data. Survival analysis was performed using the Kaplan-Meier method $^{[39]}$ and after assessing that the assumptions of the Cox model were met, proportional hazard model analysis was used to assess the effect of predictors of survival after LT. Pre-transplant characteristics utilized in the Cox regression model were selected a priori. Donor variables used as covariates for proportional hazard model were: age and BMI. Recipient variables used as covariates for Cox regression model were: age, sex, the presence of type I or II diabetes, need for dialysis prior to LT, level of education, BMI, time spent on the wait list and functional status. Survival analysis was also adjusted for cold ischemia time and for the UNOS region where the transplant surgery was performed. The UNOS region 1 was chosen as the reference category and the follow-up time was restricted to 5 years after LT. Since previous studies suggested that African Americans had the lowest post LT survival among all the ethnicities, we compared patients of African descent to patients belonging to other ethnicities.

For the calculation of the hazard ratios (HR), Caucasian ethnicity, female sex, functional status lower than $60 \%$, waiting time equal or less than 3 months, post college or graduate degree were selected as references. Adjusted HR (AHR) were calculated using Caucasian patients undergoing LT as a reference. All statistical analyses were performed using SPSS Statistics for Windows, Version 24 (IBM Corporation, United States). Statistical significance was defined when $P$ values were equal or less than 0.05 , and 2-tailed tests were used for all statistical analyses.

\section{RESULTS}

During the study period, 9723 patients were recorded in the STAR files as recipients of a cadaveric LT with HCC being the primary indication for surgery. Cold ischemia time longer than $24 \mathrm{~h}$ was logged in 13 


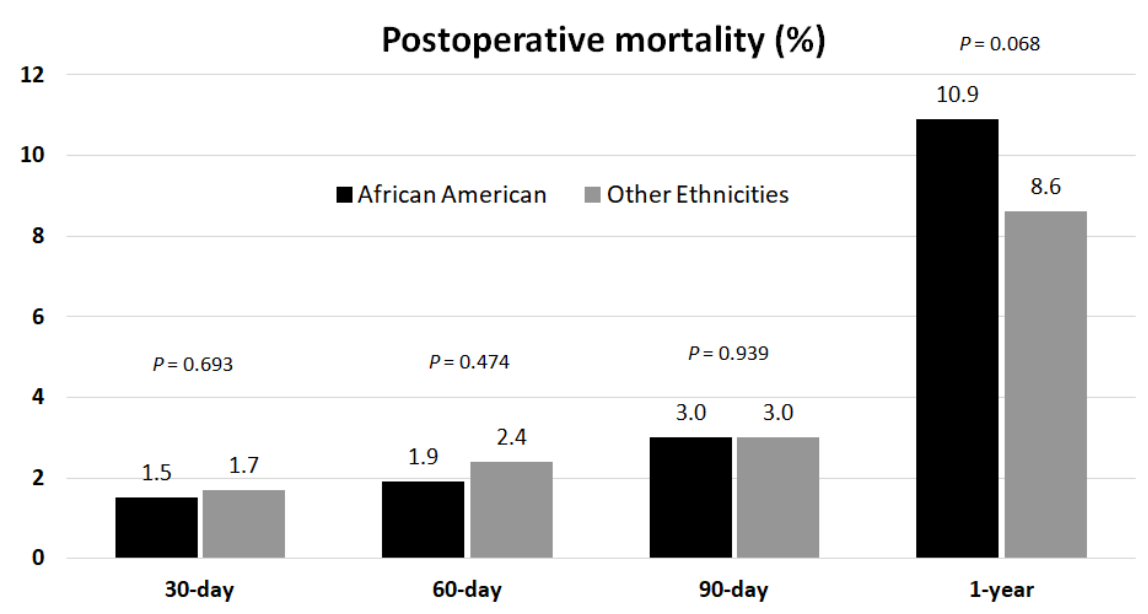

Figure 1. Analysis of the frequency of postoperative mortality observed in African American patients vs. patients of other ethnicities undergoing first-time cadaveric liver transplant for hepatocellular carcinoma at 30-, 60-, 90-day and at 1 year after surgery

recipients and 3019 patients had no HCC in their final surgical pathology report of their explanted livers and were excluded. After the additional removal of 643 recipients who had more than $10 \%$ of missing data, we identified a cohort of $6048 \mathrm{LT}$ recipients who represented the study population. The average age of the recipients was 58 years and females represented $20 \%$ of the cohort. Most patients were Caucasians (67\%), followed by Hispanics (14.2\%), African Americans (8.8\%) and Asians (8.6\%). Detailed demographic and clinical characteristics of the study population are summarized in Table 1.

\section{Clinical and socio-economic characteristics}

When compared to all other ethnic groups, the cohort of African American recipients had a higher percentage of women $(26.2 \%$ vs. $19.7 \%$; $P \leq 0.001)$, was younger with an average age of 57 years $v s$. 58 years $(P=0.005)$, had a greater proportion of patients who required hemodialysis before LT $(2.3 \% v s .0 .7 \% ; P \leq 0.001)$, had fewer patients who had to wait longer than 6 months for LT ( $34.2 \% v s .40 .8 \% ; P=0.02)$, had a lower level of education and received a graft from younger donors ( 42.6 years $v s .44 .2$ years; $P=0.030$ ). Detailed comparisons between African American patients and the rest of the cohort are reported in Table 2.

\section{Postoperative mortality and survival}

The median follow-up of the cohort was 7.6 years (95\% CI: 7.5-7.8). During this period, 2079 patients had died (34.3\%), 3762 were censored (62.2\%), and 207 patients (3.4\%) were lost at follow-up. Overall 30-, 60-, 90-day and 1-year mortality was $1.7 \%, 2.3 \%, 3.0 \%$ and $8.8 \%$ respectively with no statistically significant differences between African Americans and other ethnicities [Figure 1].

Table 3 reports the primary causes of death of patients who died within 5 years after LT. Graft failure was the most frequent cause of death among African Americans (16.6\%), followed by multiorgan failure (15.4\%) and recurrent malignancy (15.4\%). On the other hand, the most frequent known causes of deaths in patients belonging to other ethnic groups were recurrent malignancy (31.1\%), graft failure (11.4\%) and infections (9.0\%) $(P<0.001)$.

Kaplan-Meier survival function showed that the 5-year probability of survival for all patients who underwent LT for HCC was 69\% [Figure 2]. Comparisons of survival functions by ethnicity showed that African American had the lowest 5-year survival with statistically significant differences between African Americans and all the other ethnic groups $(P \leq 0.001)$ [Figure 3]. 
Table 1. Demographic and clinical characteristics of the study population (6048 liver transplant recipients)

\begin{tabular}{|c|c|}
\hline Characteristics & Value \\
\hline Age, years, mean, (SD) & $57.9(6.9)$ \\
\hline \multicolumn{2}{|l|}{$\operatorname{Sex}, n(\%)$} \\
\hline Female & $1,224(20.2)$ \\
\hline \multicolumn{2}{|l|}{ Ethnicity, $n$ (\%) } \\
\hline Caucasian & $4,054(67.0)$ \\
\hline African American & $531(8.8)$ \\
\hline Hispanic & $859(14.2)$ \\
\hline Asian & $522(8.6)$ \\
\hline Multiracial or others & $82(1.4)$ \\
\hline Recipient BMI, mean, (SD) & $28.5(5.0)$ \\
\hline \multicolumn{2}{|l|}{ Recipient BMI, category, $n$ (\%) } \\
\hline Underweight & $3(0)$ \\
\hline Normal weight & $1,535(25.4)$ \\
\hline Overweight & $2,420(41.0)$ \\
\hline Obesity class I & $1,342(22.2)$ \\
\hline Obesity class II & $545(9.0)$ \\
\hline Obesity class III & $143(2.4)$ \\
\hline Donor BMI, mean, (SD) & $27.6(5.4)$ \\
\hline Presence of renal insufficiency requiring dialysis, $n(\%)$ & $50(0.8)$ \\
\hline \multicolumn{2}{|l|}{ Presence of diabetes, $n(\%)$} \\
\hline No & $4,254(70.3)$ \\
\hline Type 1 or type 2 & $1,742(28.8)$ \\
\hline Unknown & $52(0.9)$ \\
\hline MELD score, mean, (SD) & $12.1(4.5)$ \\
\hline Hospital stay (day), mean, (SD) & $10.6(13.0)$ \\
\hline \multicolumn{2}{|l|}{ Months spent on the waiting list, $n$ (\%) } \\
\hline $0-3$ & $2,370(39.2)$ \\
\hline $3.1-6$ & $1,245(20.6)$ \\
\hline $6.1-12$ & $1242(20.5)$ \\
\hline Longer than 12 months & $1,191(19.7)$ \\
\hline \multicolumn{2}{|l|}{ Functional status at the time of transplantation, $n(\%)$} \\
\hline Less than $60 \%$ & $958(15.8)$ \\
\hline $60 \%$ or more & $4,795(79.2)$ \\
\hline Unknown & $295(4.8)$ \\
\hline \multicolumn{2}{|l|}{ Education, $n(\%)$} \\
\hline Elementary of middle school (grade 1-8) & $326(5.4)$ \\
\hline High school (grade 9-12) & $2,333(38.6)$ \\
\hline College or technical school & $1,376(22.8)$ \\
\hline Associate or bachelor degree & $805(13.3)$ \\
\hline Post-college or graduate degree & $338(5.6)$ \\
\hline Unknown & $870(14.4)$ \\
\hline \multicolumn{2}{|l|}{ UNOS region, $n(\%)$} \\
\hline Region 1 & $274(4.5)$ \\
\hline Region 2 & $605(10.0)$ \\
\hline Region 3 & $888(14.7)$ \\
\hline Region 4 & $734(12.1)$ \\
\hline Region 5 & $968(16.0)$ \\
\hline Region 6 & $301(5.0)$ \\
\hline Region 7 & $549(9.1)$ \\
\hline Region 8 & $483(8.0)$ \\
\hline Region 9 & $422(7.0)$ \\
\hline Region 10 & $512(8.5)$ \\
\hline Region 11 & $312(5.2)$ \\
\hline Donors' age, years, mean, (SD) & $41.1(15.9)$ \\
\hline Cold ischemia time, hours, mean, (SD) & $6.7(2.5)$ \\
\hline
\end{tabular}

BMI: body mass index 
Table 2. Demographic and clinical characteristics of the study population stratified by recipient ethnicity: African Americans $(8.8 \%)$ vs, other ethnicities $(91.2 \%)$

\begin{tabular}{|c|c|c|c|}
\hline Characteristics & Other Ethnicities (no. 5,517) & African American (no. 531) & $P$ value \\
\hline Age, years, mean, (SD) & $58.0(6.9)$ & $57.1(6.9)$ & 0.005 \\
\hline \multicolumn{4}{|l|}{$\operatorname{Sex}, n(\%)$} \\
\hline Female & $1,085(19.7)$ & $139(26.2)$ & $\leq 0.001$ \\
\hline Body mass index, mean, (SD) & $28.5(5.0)$ & $28.3(5.2)$ & 0.593 \\
\hline \multicolumn{4}{|l|}{ Recipient BMI, Category, $n$ (\%) } \\
\hline Underweight & $3(0.1)$ & $0(0.0)$ & \multirow{6}{*}{0.273} \\
\hline Normal weight & $1,398(25.3)$ & $137(25.8)$ & \\
\hline Overweight & $2,253(40.8)$ & $227(42.7)$ & \\
\hline Obesity class I & $1,230(22.3)$ & $112(21.1)$ & \\
\hline Obesity class II & $508(9.2)$ & $37(7.0)$ & \\
\hline Obesity class III & $125(2.3)$ & $18(3.4)$ & \\
\hline Donor BMI, mean, (SD) & $27.6(5.4)$ & $27.3(5.6)$ & 0.260 \\
\hline Presence of renal insufficiency requiring dialysis, $n$ (\%) & $38(0.7)$ & $12(2.3)$ & $\leq 0.001$ \\
\hline \multicolumn{4}{|l|}{ Presence of diabetes, $n$ (\%) } \\
\hline No & $3,867(70.1)$ & $387(72.9)$ & \multirow{3}{*}{0.226} \\
\hline Type 1 or type 2 & $1,600(29.0)$ & $142(26.7)$ & \\
\hline Unknown & $50(0.9)$ & $2(0.4)$ & \\
\hline MELD score, mean, (SD) & $12.1(4.4)$ & $12.1(5.0)$ & 0.794 \\
\hline Hospital Stay (day), mean, (SD) & $10.5(13.1)$ & $11.5(12.1)$ & 0.110 \\
\hline \multicolumn{4}{|l|}{ Months spent on the waiting list, $n$ (\%) } \\
\hline $0-3$ & $2,141(38.8)$ & $229(43.1)$ & \multirow{4}{*}{0.022} \\
\hline $3.1-6$ & $1,125(20.4)$ & $120(22.6)$ & \\
\hline $6.1-12$ & $1,142(20.7)$ & $100(18.8)$ & \\
\hline Longer than 12 months & $1,109(20.1)$ & $82(15.4)$ & \\
\hline \multicolumn{4}{|l|}{ Functional status at the time of transplantation, $n(\%)$} \\
\hline Less than $60 \%$ & $881(16)$ & $77(14.5)$ & \multirow{3}{*}{0.413} \\
\hline $60 \%$ or more & 4,372 (79.2) & $423(79.7)$ & \\
\hline Unknown & $264(4.8)$ & $31(5.8)$ & \\
\hline \multicolumn{4}{|l|}{ Education, $n(\%)$} \\
\hline Elementary of middle school (grade 1-8) & $310(5.6)$ & $16(3.0)$ & \multirow{6}{*}{0.010} \\
\hline High school (grade 9-12) & $2,110(38.3)$ & $223(42.0)$ & \\
\hline College or technical school & $1,251(22.7)$ & $125(23.5)$ & \\
\hline Associate or bachelor degree & $750(13.6)$ & $55(10.4)$ & \\
\hline Post college or graduate degree & $314(5.7)$ & $24(4.5)$ & \\
\hline Unknown & $781(14.2)$ & $88(16.6)$ & \\
\hline \multicolumn{4}{|l|}{ UNOS region, $n(\%)$} \\
\hline Region 1 & $256(93.4)$ & $18(6.6)$ & \\
\hline Region 2 & $485(80.2)$ & $120(19.8)$ & \\
\hline Region 3 & $804(90.5)$ & $84(9.5)$ & \\
\hline Region 4 & $685(93.3)$ & $49(6.7)$ & \\
\hline Region 5 & $927(95.8)$ & $41(4.2)$ & \\
\hline Region 6 & $295(98.0)$ & $6(2.0)$ & $\leq 0.001$ \\
\hline Region 7 & $514(93.6)$ & $35(9.5)$ & \\
\hline Region 8 & $439(90.9)$ & $44(9.1)$ & \\
\hline Region 9 & $382(90.5)$ & $40(9.5)$ & \\
\hline Region 10 & $454(88.7)$ & $58(11.3)$ & \\
\hline Region 11 & $276(88.5)$ & $36(11.5)$ & \\
\hline Donors' age, years, mean, (SD) & $44.2(15.9)$ & $42.6(16.0)$ & 0.030 \\
\hline Cold ischemia time, hours, mean, (SD) & $6.7(2.5)$ & $6.6(2.5)$ & 0.393 \\
\hline
\end{tabular}

BMI: body mass index

At univariate Cox regression analysis, ethnicity, age, history of diabetes and functional status at the time of transplantation were independent predictors of survival after LT. At multivariate analysis, African American ethnicity remained the strongest independent predictor for increased mortality in comparison to Caucasian 
Table 3. Primary cause of death after cadaveric liver transplantation for hepatocellular carcinoma by recipient ethnicity

\begin{tabular}{lccc}
\hline The primary cause of death, $\boldsymbol{n}(\%)$ & Other ethnicities, $\boldsymbol{n}(\%)$ & African American, $\boldsymbol{n}(\%)$ & $\boldsymbol{P}$ value \\
\hline Cardiovascular & $101(7.7)$ & $19(11.2)$ & 0.185 \\
Graft failure & $150(11.4)$ & $28(16.6)$ & 1.115 \\
Cerebrovascular complications & $16(1.2)$ & $3(1.8)$ & 0.622 \\
Pulmonary complications & $46(3.5)$ & $7(4.1)$ & 0.766 \\
Renal insufficiency & $11(0.8)$ & $2(1.2)$ & 0.664 \\
Multiorgan failure & $95(7.2)$ & $26(15.4)$ & 0.001 \\
Infections & $119(9.0)$ & $15(8.9)$ & 0.810 \\
Hemorrhagic complications & $31(2.3)$ & $2(1.2)$ & 0.305 \\
Malignancy & $408(31.1)$ & $26(15.4)$ & 0.001 \\
Unknown & $333(25.4)$ & $41(24.3)$ & 0.554 \\
Total number (\%) & $1310(100)$ & $169(100)$ & - \\
\hline
\end{tabular}

recipients (reference group) (HR $=1.524 ; 95 \%$ CI: 1.283-1.803; $P<0.001$ ) after adjusting for the recipient and donor age, recipient sex, recipient history of diabetes and recipient functional status at the time of transplantation [Table 4].

\section{DISCUSSION}

Over the past decades, there has been an increasing awareness that cancers have unique mutations in signaling pathways ${ }^{[40]}$ and that patient socio-economic factors and ethnicity might play a significant role in short and long-term outcomes ${ }^{[41]}$. Contrary to the new genomic techniques that have shown biological differences among cancers of similar type ${ }^{[42]}$, causes responsible for of health disparities among patients of different socio-economic status or ethnicities remain unclear.

Socio-economic conditions are difficult to define and may fluctuate over time ${ }^{[43]}$. Several studies have shown that vulnerable socio-economic groups are less likely to undergo screening or surveillance programs for HCC and are less likely to be treated ${ }^{[24,32,4-46]}$ but possible ethnical differences in the long-term survival after LT for HCC remains poorly studied ${ }^{[47]}$.

In a retrospective analysis of 754 patients with HCC eligible for LT at Mount Sinai Hospital in New York between 2003 and 2013, Sarpel et al. ${ }^{[27]}$ found that the odds of being transplanted were significantly lower for African Americans than Caucasians ( $\mathrm{OR}=0.55,95 \%$ CI: 0.33-0.91). They also analyzed all the steps necessary for the evaluation and listing of these patients in the hope of finding barriers that could be removed in the future, but they were unable to identify any specific one. Similarly, Siegel et al ${ }^{[23]}$ investigated the Surveillance, Epidemiology, and End Results (SEER) database with the main focus of assessing if there were racial disparities in utilization of LT in patients with HCC. They found that during the period between 1998 and 2002, African Americans and Asians were less likely to receive a LT than other ethnic groups. Because of the lack of granular data on many socio-economic factors, the authors were unable to identify the main reasons for those differences, but they hypothesized that access to transplant centers, referral bias, comorbidity and severy of underlying liver disease might have been the main causes why African Americans and Asian Americans had lower rates of LT. Similar findings were reported by other investigators ${ }^{[30,48]}$.

More recently, Moylan et al. ${ }^{[49]}$ have found that African American were less likely to receive a LT (OR 0.75; 95\% CI: 0.59-0.97) during the pre-MELD era and were more likely to die or become too sick for transplant compared to Caucasians (OR 1.51; 95\% CI: 1.15-1.98). However, after changes in the allocation of liver grafts that occurred with the introduction of the MELD score, ethnicity was no longer associated with waitlist death or lower rate of LT. 
Table 4. Univariate and Multivariate Cox proportional hazard model of mortality of patients undergoing cadaveric liver transplantation for hepatocellular carcinoma. The adjusted Hazard Ratio was casculated by including both clinical and sociodemographic characteristics

\begin{tabular}{|c|c|c|c|c|c|c|}
\hline Chracteristics & $\begin{array}{l}\text { Unadjusted } \\
\text { HR }\end{array}$ & $95 \% \mathrm{Cl}$ & $\begin{array}{l}P \text { value for } \\
\text { unadjusted } \\
\text { HR }\end{array}$ & $\begin{array}{l}\text { Adjusted } \\
\text { HR }\left({ }^{\star}\right)\end{array}$ & $95 \% \mathrm{Cl}$ & $\begin{array}{l}P \text { value for } \\
\text { adjusted HR }\end{array}$ \\
\hline Recipient ethnicity & & & $<0.001$ & & & $<0.001$ \\
\hline Caucasian (reference) & 1 & & & 1 & & \\
\hline African American & 1.484 & $1262-1.746$ & $<0.001$ & 1.524 & $1.283-1.803$ & $<0.001$ \\
\hline Hispanic & 0.799 & $0.679-0.939$ & 0.007 & 0.785 & $0.656-0.940$ & 0.008 \\
\hline Asian & 0.602 & $0.483-0.751$ & $<0.001$ & 0.618 & $0.485-0.787$ & $<0.001$ \\
\hline Multiracial or Other Ethnicities & 0.610 & $0.360-1.033$ & 0.066 & 0.733 & $0.431-1.246$ & 0.251 \\
\hline Donor age (year) & 1.010 & $1.007-1.014$ & $<0.001$ & 1.010 & $1.007-1.014$ & $<0.001$ \\
\hline Recipient age (year) & 1.020 & $1.012-1.028$ & $<0.001$ & 1.019 & $1.010-1.027$ & $<0.001$ \\
\hline Recipient sex (female as reference) & 1 & & & 1 & & \\
\hline Male & 0.935 & $0.822-1.063$ & 0.306 & 0.988 & $0.861-1.134$ & 0.697 \\
\hline Donor BMI & 1.006 & $0.997-1.016$ & 0.193 & 1.002 & $0.991-1.012$ & 0.766 \\
\hline Recipient BMI & 1.002 & $0.992-1.013$ & 0.714 & 0.996 & $0.985-1.008$ & 0.788 \\
\hline Cold ischemia time (hour) & 1.018 & $0.998-1.038$ & 0.082 & 1.013 & $0.992-1.034$ & 0.233 \\
\hline Presence of diabetes (Type 1 or 2 ) & 1.182 & $1.029-1.270$ & 0.013 & 1.065 & $0.567-2.000$ & 0.844 \\
\hline Dialysis prior to transplant & 1.263 & $0.731-2.181$ & 0.420 & 1.109 & $0.612-2.009$ & 0.734 \\
\hline MELD score & 1.005 & $0.994-1.017$ & 0.370 & 1.002 & $0.989-1.014$ & 0.812 \\
\hline Functional status at the time of transplantation & & & $<0.001$ & & & $<0.001$ \\
\hline Functional status $<60 \%$ (reference) & 1 & & & 1 & & \\
\hline Functional status $\geq 60 \%$ & 0.752 & $0.617-0.918$ & 0.005 & 0.696 & $0.602-0.806$ & 0.044 \\
\hline UNOS region & & & 0.165 & & & 0.149 \\
\hline Region 1 (reference) & 1 & & 1 & 1 & & \\
\hline Region 2 & 1.27 & $0.955-1.690$ & 0.101 & 1.216 & $0.897-1.649$ & 0.207 \\
\hline Region 3 & 1.181 & $0.900-1.551$ & 0.230 & 1.216 & $0.903-1.637$ & 0.198 \\
\hline Region 4 & 0.904 & $0.679-1.203$ & 0.489 & 1.010 & $0.742-1.374$ & 0.951 \\
\hline Region 5 & 0.824 & $0.623-1.089$ & 0.174 & 0.906 & $0.669-1.225$ & 0.521 \\
\hline Region 6 & 0.913 & $0.661-1.262$ & 0.582 & 1.097 & $0.778-1.546$ & 0.598 \\
\hline Region 7 & 0.978 & $0.728-1.315$ & 0.883 & 0.989 & $0.723-1.354$ & 0.947 \\
\hline Region 8 & 0.882 & $0.647-1.204$ & 0.430 & 0.983 & $0.708-1.365$ & 0.918 \\
\hline Region 9 & 1.264 & $0.942-1.695$ & 0.118 & 1.171 & $0.854-1.604$ & 0.326 \\
\hline Region 10 & 1.139 & $0.852-1.522$ & 0.381 & 1.217 & $0.887-1.668$ & 0.223 \\
\hline Region 11 & 1.279 & $0.930-1.758$ & 0.130 & 1.286 & $0.909-1.820$ & 0.155 \\
\hline Waiting time (month) & & & 0.390 & & & 0.430 \\
\hline 0-3 months (reference) & 1 & & & 1 & & \\
\hline 3.1-6 months & 1.050 & $0.914-1.206$ & 0.489 & 1.110 & $0.955-1.291$ & 0.172 \\
\hline 6.1-12 months & 0.908 & $0.782-1.054$ & 0.206 & 0.995 & $0.842-1.177$ & 0.956 \\
\hline$>12$ months & 0.966 & $0.835-1.118$ & 0.643 & 1.085 & $0.922-1.278$ & 0.324 \\
\hline Education & & & 0.064 & & & 0.173 \\
\hline Elementary of middle school (grade 0-8) & 0.964 & $0.750-1.240$ & 0.512 & 1.146 & $0.877-1.497$ & 0.317 \\
\hline High school (grade 9-12) & 0.915 & $0.790-1.060$ & 0.182 & 0.969 & $0.827-1.135$ & 0.697 \\
\hline College or technical school & 0.819 & $0.693-0.967$ & 0.013 & 0.882 & $0.738-1.053$ & 0.164 \\
\hline Associate or bachelor degree & 0.831 & $0.686-1.007$ & 0.014 & 0.891 & $0.728-1.091$ & 0.082 \\
\hline Post college or graduate degree (reference) & 1 & & & 1 & & \\
\hline
\end{tabular}

The adjusted HR $\left(^{*}\right)$ was calculated including clinical and sociodemographic variables. Clinical characteristics used for the adjustment were: donor and recipient age, recipient sex, recipient body mass index (BMI), MELD score, history of diabetes and dialysis, functional status. Social characteristics used for the adjustment were the highest level of education obtained by the recipient. The surgical characteristic used for the adjustment was the cold ischemia time. Other characteristics used for the adjustment of the HR were the UNOS region where the transplant occurred and the length of waiting time

Despite these positive changes, other investigators continued to report that African Americans have the lowest survival rate among all LT recipients for benign conditions ${ }^{[31-33,50,51]}$. These findings were confirmed by Wong et al. ${ }^{[30]}$ who analyzed the STAR files from 2002 to 2012 and found that African American with HCC 


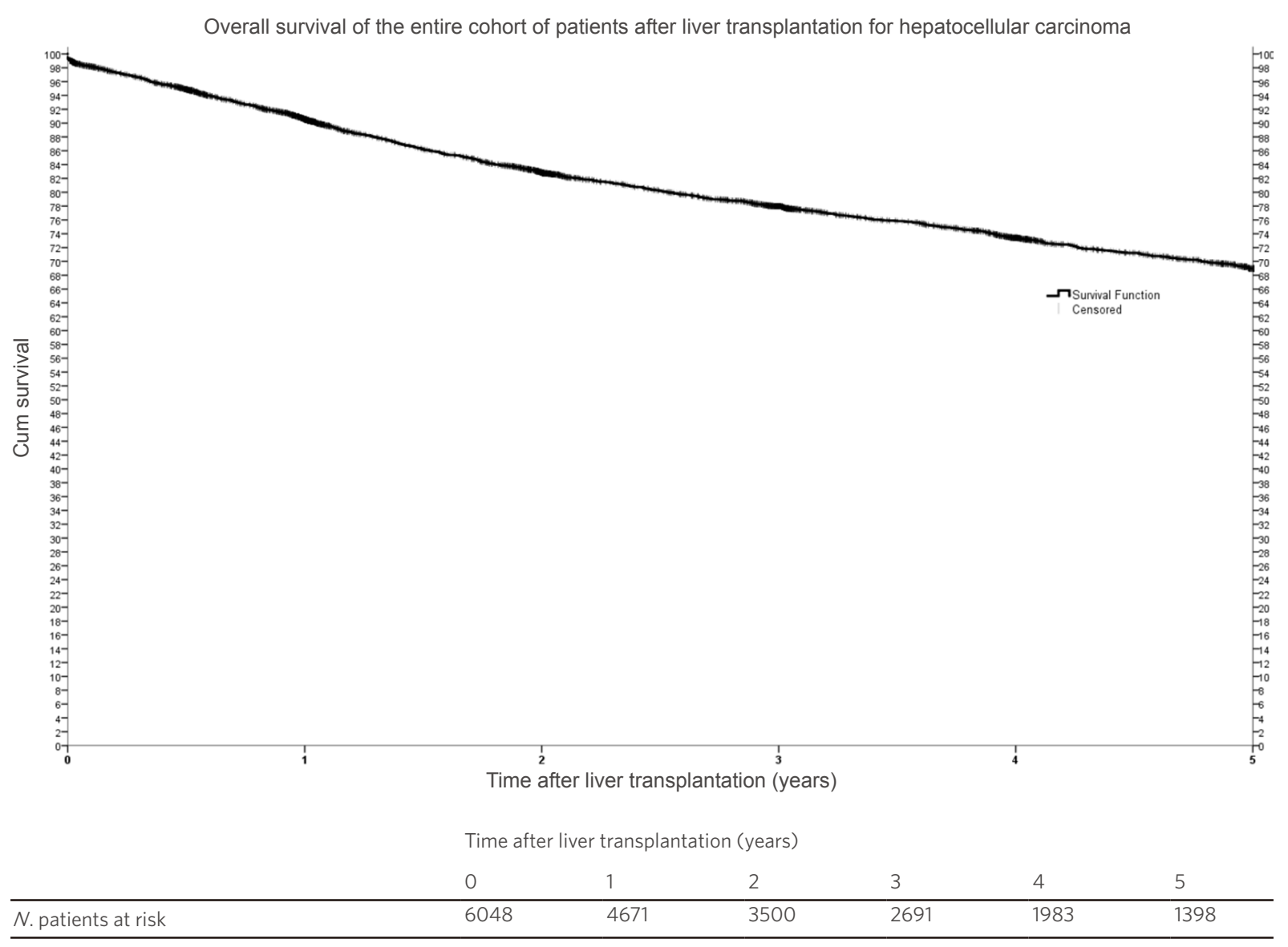

Figure 2. Kaplan Meier survival function representing the 5-year overall survival of all patients undergoing liver transplantation in the United States from 1 Jan, 2002 to 30 Jun, 2013

(HR, 1.49; 95\% CI: 1.25-1.79), HCV (HR 1.30; 95\% CI: 1.19-1.41) and alcoholic liver disease (HR 1.52; 95\% CI: 1.19-1.94) had inferior survival compared to other ethnic groups. One of the limitations of previous studies was the fact that they did not to adjust survival analyses for known risk factors such as donor characteristics, cold ischemia time, recipient comorbidities and did not exclude patients whose explanted liver did not have HCC.

Therefore, we analyzed only LT recipients with confirmed HCC with the main intent of testing the null hypothesis that after adjusting for clinical and socio-economic factors, African Americans should have short and long-term outcomes comparable to other ethnic groups. When compared to other ethnicities, we found that African Americans had lower education level, were more frequently affected by renal dysfunction requiring dialysis $(2.3 \%$ vs. $0.7 \%)$ and had a shorter period on the waiting list. Although 30-, 60-, 90-day postoperative mortality was similar between African American and other ethnic groups, their 1-year mortality was higher and their survival started to diverge from all the other ethnicities.

Only $56 \%$ of African Americans were alive after 5 years vs. $68 \%$ of Caucasians $(P \leq 0.001), 73 \%$ of Hispanics $(P \leq 0.001)$ and $79 \%-81 \%$ of Asians and other minorities $(P \leq 0.001)$. Multivariate analysis confirmed that African American ethnicity remained the strongest independent predictor of lower survival (HR 1.5; 95\% CI: 1.2-1.8) after adjusting for donor and recipient age, sex, BMI, cold ischemia, diabetes and renal insufficiency, MELD score, functional status, waiting time, level of education and UNOS region. These findings rejected our original hypothesis that the outcomes of LT recipients with HCC should be similar among different ethnic groups. 


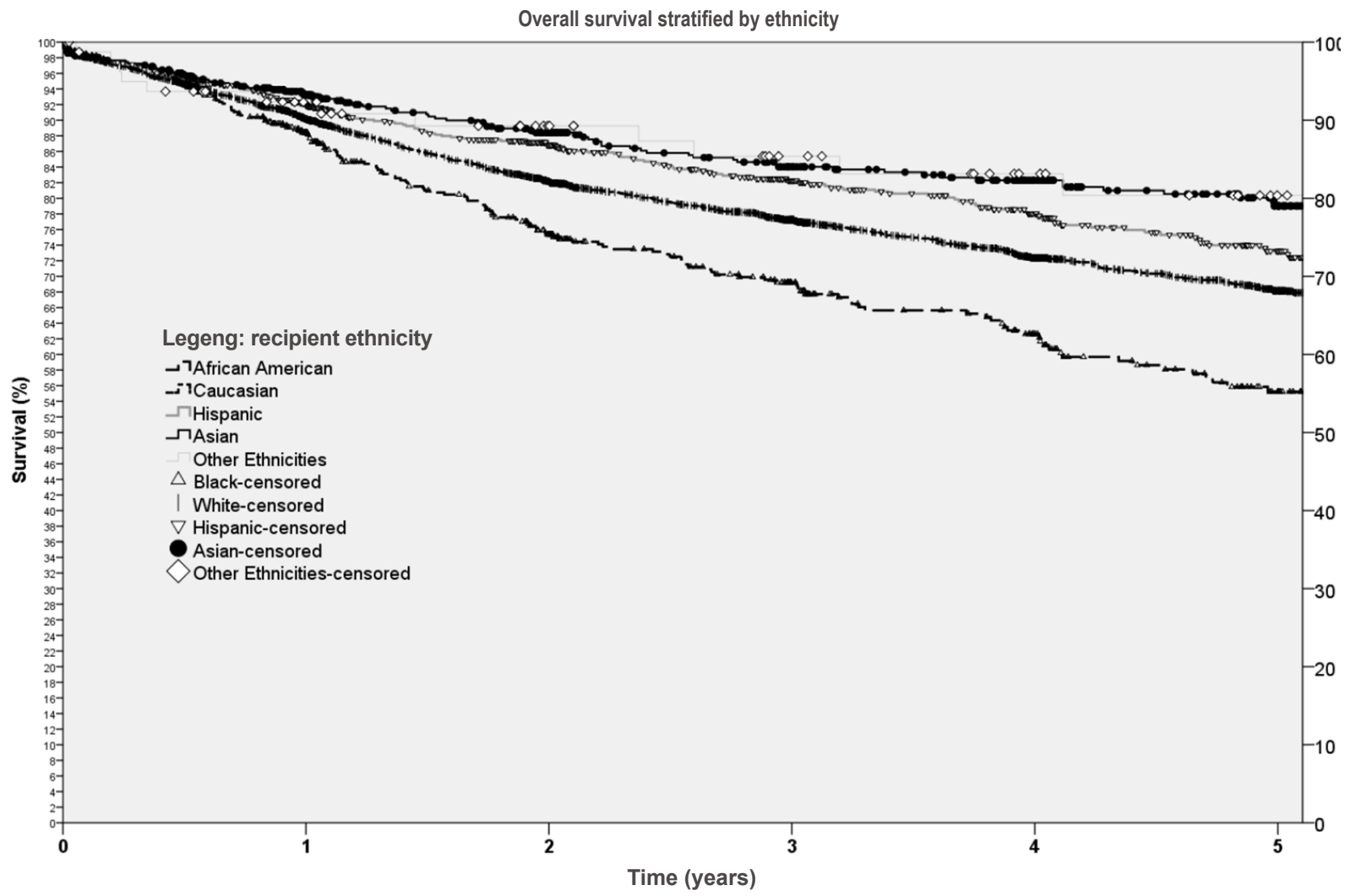

\begin{tabular}{lllllll}
\multicolumn{1}{l}{ Time after liver transplantation (years) } \\
\cline { 2 - 7 } N. patients at risk & 0 & 1 & 2 & 3 & 4 & 5 \\
\hline African Americans & 531 & 395 & 275 & 202 & 142 & 89 \\
Caucasians & 4,054 & 3,124 & 2,329 & 1,790 & 1,295 & 922 \\
Hispanics & 859 & 669 & 509 & 382 & 295 & 196 \\
Asians & 522 & 416 & 333 & 274 & 215 & 161 \\
Multiracial or other minorities & 82 & 66 & 52 & 40 & 32 & 25 \\
\hline
\end{tabular}

Figure 3. Kaplan-Meier survival functions of patients undergoing liver transplantation for hepatocellular carcinoma in the United States stratified by ethnicity. The probability of 5 -year survival was $81 \%$ for patients belonging to multiracial or other minorities, $79 \%$ for Asians, $73 \%$ for Hispanics, 68\% for Caucasians and $56 \%$ for African American $(P \leq 0.001)$

Patients who undergo LT are only a fraction of the number of patients who are referred but fail selection due to insufficient social support, inability to travel to transplant centers or lack of resources including healthcare insurance. And, since most of the transplant centers in the United States use comparable criteria for screening patients with inadequate socio-economic resources, and use the Milan criteria for staging HCC irrespective of patient ethnicity, we advanced the hypothesis that unless there were biological reasons, there should not be significant ethnic differences in outcomes after LT.

Overall the results of this study are not novel, yet there are several methodological differences that distinguish our study from others. First of all, we included only patients who had documented HCC in their explanted livers. Confirmation that all recipients in this study had HCC is important because up to $11 \%$ of patients who are diagnosed with HCC by imaging tests without biopsy prior to LT end up having no pathological evidence of neoplastic lesions in their explanted livers ${ }^{[52]}$. Second, before we analyzed the longterm outcomes, we confirmed that there were no significant differences in perioperative mortality between African Americans and other ethnic groups. Proving that the risk of death at 30-, 60-, and 90-day after LT was similar between the two groups supported the concept that there were no fundamental differences in 
pre-existing conditions among different ethnic groups. Third, we performed a multivariable analysis to assess if ethnicity was an independent predictor of patient survival after adjusting for many clinical and demographic factors selected a priori. Among these factors, we included patient characteristics as well as donor and intraoperative variables shown to be associated with long-term outcomes such as cold ischemia time, donor age as proxy for the quality of the liver grafts, history of diabetes, presence of renal failure requiring dialysis prior to transplantation and recipient functional status ${ }^{[53]}$.

To the best of our knowledge, our study is also the very first to explore if the causes of death after LT were different between African Americans and other ethnic groups. We found that the primary causes of death were similar between African Americans and other ethnic groups except that African Americans had a twofold risk dying of multiorgan failure ( $15.4 \%$ vs. $7.2 \%)$ and half the risk of developing recurrent HCC or new onset of other malignancies $(15.4 \%$ vs. $31.1 \%)$. Although these findings are provocative and would suggest the presence of biological differences among ethnic groups, further investigations are needed as these results might be due to reporting bias, misdiagnosis or erroneous data entry.

Besides the retrospective design of this study, there are several other limitations that are worth mentioning. Although the STAR files have the advantage of containing data on a very large number of transplant recipients, it does not provide enough granularity on the type of insurance, socio-economic status and other personal information that might be important when trying to analyze the impact of socio-economic factors on recipients outcomes and it is subject to data entry errors and miscoding. It is well known that the introduction of random errors reduces the reliability of studies making significant findings less likely ${ }^{[54]}$. Therefore, although we recognize the existence of some degree of inaccuracy in the dataset, we suspect that miscoding had occurred randomly with no differences in the frequency of events among ethnic groups. Another limitation is the fact that, there is lack of clear definitions of ethnicities ${ }^{[55]}$. Therefore, stratifications of outcomes in this and all other previous studies were performed using self-reported ethnicity. This process has been the norm for health researchers, but self-reporting is a moderate to weak substitution for ancestral genotyping $^{[56]}$. Consequently, our results have to be interpreted with some caution since overlapping between ethnic groups is expected. In addition, while our survival analyses were adjusted for many important variables, certain factors that may affect post LT survival such as adherence, HCV status or differences in the pharmacodynamic of immunosuppression medications were not available.

The effect of ethnicity on the pharmacokinetic of commonly used immunosuppressive agents is often underestimated. In a study on immunocompetence between African Americans and Caucasians, Nagashima et al.$^{[57]}$ found that, among patients receiving a tacrolimus-based regimen, African Americans had reduced immunosuppressive effects in comparison to Caucasians with an increased risk of acute cellular and chronic graft rejection ${ }^{[58,59]}$. Regarding HCV status, Velidedeoglu et al. ${ }^{[60]}$ found that recipient ethnicity was an independent predictor of survival only in recipients affected by HCV. These findings suggested that the lower survival observed in African Americans may be related to the presence of hepatitis $\mathrm{C}$ rather than socioeconomic conditions. Unfortunately, due to many missing data on the HCV status of patients with HCC, we were unable to adjust for this important factor. Since the introduction of new antiviral medications that provide sustained virological response in African Americans similar to other ethnic groups, we suspect that HCV positive status will play a very small role in the overall survival of patients undergoing LT in the future.

In conclusion, the findings of our study are several. The first is that the short-term outcomes of African American recipients of cadaveric LTs for HCC are similar to patients belonging to other ethnicities. Second, we confirme that African Americans have the lowest 5-year survival rate among all the ethnic groups after adjusting for several clinical and socio-demographic characterstics. Third, that African American ethnicity and poor functional status at the time of LT are the two strongest predictors of inferior survival. 
Previous investigators have suggested that differences in the socioeconomic status might be responsible for the lowest survival observed among African Americans. We recognize that there are many factors that were not accounted in our analysis such as type of health care insurance, household income, serum alpha-fetoprotein, number and size of the largest tumor, cellular differentiation and vascular invasion. However, due to similar oncological and socio-economic criteria equally applied across all ethnicities during the evaluation and selection of LT recipients, there might be biological reasons, rather than socio-economic factors responsible for the survival differences observed among ethnic groups undergoing LT for HCC.

\section{DECLARATIONS}

\section{Authors' contributions}

Michele Molinari designed the study, performed the statistical analysis and wrote the manuscript, Allan Tsung reviewed the statistical analysis and the manuscript, Subhashini Ayloo designed the study, reviewed the manuscript and the statistical analysis, Patrick Bou Samra revised the manuscript and performed the review of the literature, Naudia Jonassaint designed the study, reviewed the manuscript and the statistical analysis.

\section{Availability of data and materials}

Data and materials are available from the corresponding author on reasonable request.

\section{Financial support and sponsorship}

None.

\section{Conflicts of interest}

The authors declare that there are no conflicts of interest related to this study.

\section{Ethical approval and consent to participate}

Not applicable.

\section{Consent for publication}

Not applicable.

\section{Copyright}

(c) The Author(s) 2018.

\section{REFERENCES}

1. Bosch FX, Ribes J, Borras J. Epidemiology of primary liver cancer. Semin Liver Dis 1999;19:271-85.

2. Munoz N, Lingao A, Lao J, Esteve J, Viterbo G, Domingo EO, Lansang MA. Patterns of familial transmission of HBV and the risk of developing liver cancer: a case-control study in the Philippines. Int J Cancer 1989;44:981-4.

3. Wilson LB, DeMaria PA Jr., Kane HL, Reining KM. Anesthesia-assisted rapid opiate detoxification: a new procedure in the postanesthesia care unit. J Perianesth Nurs 1999;14:207-12; quiz 13-6.

4. Parkin DM, Bray F, Ferlay J, Pisani P. Global cancer statistics, 2002. CA Cancer J Clin 2005;55:74-108.

5. El-Serag HB. Hepatocellular carcinoma: recent trends in the United States. Gastroenterology 2004;127:S27-34.

6. Cwinn M, Walsh G, Rahman SH, Molinari M. The geography of primary hepatic neoplasms treatments in Canada: changes in latitudes and changes in attitudes. Can J Gastroenterol Hepatol 2017;2017:9365657.

7. Llovet JM. Updated treatment approach to hepatocellular carcinoma. J Gastroenterol 2005;40:225-35.

8. Llovet JM, Sala M. Non-surgical therapies of hepatocellular carcinoma. Eur J Gastroenterol Hepatol 2005;17:505-13.

9. Fuster J, Charco R, Llovet JM, Bruix J, Garcia-Valdecasas JC. Liver transplantation in hepatocellular carcinoma. Transpl Int 2005;18:27882.

10. Sherman M. Modern approach to hepatocellular carcinoma. Curr Gastroenterol Rep 2011;13:49-55.

11. Bruix J, Sherman M, American Association for the Study of Liver D. Management of hepatocellular carcinoma: an update. Hepatology 2011;53:1020-2.

12. Trinchet JC, Beaugrand M. Treatment of hepatocellular carcinoma in patients with cirrhosis. J Hepatol 1997;27:756-65.

13. Chen MF, Hwang TL, Jeng LB, Wang CS, Jan YY, Chen SC. Postoperative recurrence of hepatocellular carcinoma. Two hundred five 
consecutive patients who underwent hepatic resection in 15 years. Arch Surg 1994;129:738-42.

14. Zhou XD, Tang ZY, Yang BH, Lin ZY, Ma ZC, Ye SL, Wu ZQ, Fan J, Qin LX, Zheng BH. Experience of 1000 patients who underwent hepatectomy for small hepatocellular carcinoma. Cancer 2001;91:1479-86.

15. Mazzaferro V, Regalia E, Doci R, Andreola S, Pulvirenti A, Bozzetti F, Montalto F, Ammatuna M, Morabito A, Gennari L. Liver transplantation for the treatment of small hepatocellular carcinomas in patients with cirrhosis. N Engl J Med 1996;334:693-9.

16. Allgaier HP, Deibert P, Zuber I, Olschewski M, Blum HE. Percutaneous radiofrequency interstitial thermal ablation of small hepatocellular carcinoma. Lancet 1999;353:1676-7.

17. Mor E, Kaspa RT, Sheiner P, Schwartz M. Treatment of hepatocellular carcinoma associated with cirrhosis in the era of liver transplantation. Ann Intern Med 1998;129:643-53.

18. Iwatsuki S, Starzl TE, Sheahan DG, Yokoyama I, Demetris AJ, Todo S, Tzakis AG, Van Thiel DH, Carr B, Selby R. Hepatic resection versus transplantation for hepatocellular carcinoma. Ann Surg 1991;214:221-8; discussion 8-9.

19. Poon RT, Fan ST, Lo CM, Ng IO, Liu CL, Lam CM, Wong J. Improving survival results after resection of hepatocellular carcinoma: a prospective study of 377 patients over 10 years. Ann Surg 2001;234:63-70.

20. Nagashima I, Hamada C, Naruse K, Osada T, Nagao T, Kawano N, Muto T. Surgical resection for small hepatocellular carcinoma. Surgery 1996;119:40-5

21. Bismuth H, Majno PE, Adam R. Liver transplantation for hepatocellular carcinoma. Semin Liver Dis 1999;19:311-22.

22. Akriviadis EA, Llovet JM, Efremidis SC, Shouval D, Canelo R, Ringe B, Meyers WC. Hepatocellular carcinoma. Br J Surg 1998;85:131931.

23. Siegel AB, McBride RB, El-Serag HB, Hershman DL, Brown RS Jr., Renz JF, Emond J, Neugut AI. Racial disparities in utilization of liver transplantation for hepatocellular carcinoma in the United States, 1998-2002. Am J Gastroenterol 2008;103:120-7.

24. Bryce CL, Chang CC, Angus DC, Arnold RM, Farrell M, Roberts MS. The Effect of race, sex, and insurance status on time-to-listing decisions for liver transplantation. J Transplant 2010;2010:467976.

25. Yu JC, Neugut AI, Wang S, Jacobson JS, Ferrante L, Khungar V, Lim E, Hershman DL, Brown RS, Jr., Siegel AB. Racial and insurance disparities in the receipt of transplant among patients with hepatocellular carcinoma. Cancer 2010;116:1801-9.

26. Kish JK, Yu M, Percy-Laurry A, Altekruse SF. Racial and ethnic disparities in cancer survival by neighborhood socioeconomic status in Surveillance, Epidemiology, and End Results (SEER) Registries. J Natl Cancer Inst Monogr 2014;2014:236-43.

27. Sarpel U, Suprun M, Sofianou A, Berger Y, Tedjasukmana A, Sekendiz Z, Bagiella E, Schwartz ME. Disentangling the effects of race and socioeconomic factors on liver transplantation rates for hepatocellular carcinoma. Clin Transplant 2016;30:714-21.

28. Vandenbroucke JP. Analytic approaches to observational studies with treatment selection bias. JAMA 2007;297:2077-8; auhor reply 8.

29. Vandenbroucke JP, von Elm E, Altman DG, Gotzsche PC, Mulrow CD, Pocock SJ, Poole C, Schlesselman JJ, Egger M, Initiative S. Strengthening the Reporting of Observational Studies in Epidemiology (STROBE): explanation and elaboration. Epidemiology 2007; $18: 805-35$

30. Wong RJ, Ahmed A. Combination of racial/ethnic and etiology/disease-specific factors is associated with lower survival following liver transplantation in African Americans: an analysis from UNOS/OPTN database. Clin Transplant 2014;28:755-61.

31. Kemmer N, Neff G, Secic M, Zacharias V, Kaiser T, Buell J. Ethnic differences in hepatocellular carcinoma: implications for liver transplantation. Dig Dis Sci 2008;53:551-5.

32. Ananthakrishnan AN, Saeian K. Racial differences in liver transplantation outcomes in the MELD era. Am J Gastroenterol 2008;103:90110 .

33. Nair S, Eustace J, Thuluvath PJ. Effect of race on outcome of orthotopic liver transplantation: a cohort study. Lancet 2002;359:287-93.

34. Lee TH, Shah N, Pedersen RA, Kremers WK, Rosen CB, Klintmalm GB, Kim WR. Survival after liver transplantation: is racial disparity inevitable? Hepatology 2007:46:1491-7.

35. Ayloo S, Hurton S, Cwinn M, Molinari M. Impact of body mass index on outcomes of 48281 patients undergoing first time cadaveric liver transplantation. World J Transplant 2016;6:356-69.

36. Tapper EB, Su GL. Does Karnofsky Performance Status of patients with cirrhosis on the transplant waitlist meet the eyeball test? Clin Gastroenterol Hepatol 2016;14:1196-8.

37. Tandon P, Reddy KR, O’Leary JG, Garcia-Tsao G, Abraldes JG, Wong F, Biggins SW, Maliakkal B, Fallon MB, Subramanian RM, Thuluvath P, Kamath PS, Thacker LR, Bajaj JS, North American Consortium for the Study of End-Stage Liver D. A Karnofsky performance status-based score predicts death after hospital discharge in patients with cirrhosis. Hepatology 2017;65:217-24.

38. de Kock I, Mirhosseini M, Lau F, Thai V, Downing M, Quan H, Lesperance M, Yang J. Conversion of Karnofsky Performance Status (KPS) and Eastern Cooperative Oncology Group Performance Status (ECOG) to Palliative Performance Scale (PPS), and the interchangeability of PPS and KPS in prognostic tools. J Palliat Care 2013;29:163-9.

39. Strauss D, Shavelle R. An extended Kaplan-Meier estimator and its applications. Stat Med 1998;17:971-82.

40. Kalia M. Personalized oncology: recent advances and future challenges. Metabolism 2013;62 Suppl 1:S11-4.

41. Hoffman RM, Gilliland FD, Eley JW, Harlan LC, Stephenson RA, Stanford JL, Albertson PC, Hamilton AS, Hunt WC, Potosky AL. Racial and ethnic differences in advanced-stage prostate cancer: the prostate cancer outcomes study. J Natl Cancer Inst 2001;93:388-95.

42. Siegel R, DeSantis C, Virgo K, Stein K, Mariotto A, Smith T, Cooper D, Gansler T, Lerro C, Fedewa S, Lin C, Leach C, Cannady RS, Cho H, Scoppa S, Hachey M, Kirch R, Jemal A, Ward E. Cancer treatment and survivorship statistics, 2012. CA Cancer J Clin 2012;62:220-41.

43. Luedi PP, Dietrich FS, Weidman JR, Bosko JM, Jirtle RL, Hartemink AJ. Computational and experimental identification of novel human imprinted genes. Genome Res 2007;17:1723-30.

44. Shah SA, Smith JK, Li Y, Ng SC, Carroll JE, Tseng JF. Underutilization of therapy for hepatocellular carcinoma in the medicare population. Cancer 2011;117:1019-26

45. Nathan H, Hyder O, Mayo SC, Hirose K, Wolfgang CL, Choti MA, Pawlik TM. Surgical therapy for early hepatocellular carcinoma in the modern era: a 10-year SEER-medicare analysis. Ann Surg 2013;258:1022-7. 
46. Alawadi ZM, Phatak UR, Kao LS, Ko TC, Wray CJ. Race not rural residency is predictive of surgical treatment for hepatocellular carcinoma: analysis of the texas Cancer Registry. J Surg Oncol 2016;113:84-8.

47. Kemmer N, Neff GW. Ethnic variations in chronic liver diseases. Dig Dis Sci 2008;53:1339-44.

48. Xing M, Kim HS. Independent prognostic factors for posttransplant survival in hepatocellular carcinoma patients undergoing liver transplantation. Cancer Med 2017;6:26-35.

49. Moylan CA, Brady CW, Johnson JL, Smith AD, Tuttle-Newhall JE, Muir AJ. Disparities in liver transplantation before and after introduction of the MELD score. JAMA 2008;300:2371-8.

50. Neff GW, Kemmer N, Kaiser T, Zacharias V, Majoras N, Safdar K. Outcomes in adult and pediatric liver transplantation among various ethnic groups. Transplant Proc 2007;39:3204-6.

51. Thuluvath PJ, Guidinger MK, Fung JJ, Johnson LB, Rayhill SC, Pelletier SJ. Liver transplantation in the United States, 1999-2008. Am J Transplant 2010;10:1003-19.

52. Mehta N, Dodge JL, Roberts JP, Hirose R, Yao FY. Misdiagnosis of hepatocellular carcinoma in patients receiving no local-regional therapy prior to liver transplant: an analysis of the organ procurement and transplantation network explant pathology form. Clin Transplant 2017;31.

53. Lai JC, Feng S, Terrault NA, Lizaola B, Hayssen H, Covinsky K. Frailty predicts waitlist mortality in liver transplant candidates. Am J Transplant 2014;14:1870-9.

54. Sutton GP, Barchard KA, Bello DT, Thaler NS, Ringdahl E, Mayfield J, Allen DN. Beery-Buktenica Developmental Test of Visual-Motor Integration performance in children with traumatic brain injury and attention-deficit/hyperactivity disorder. Psychol Assess 2011;23:805-9.

55. Royal CD, Dunston GM. Changing the paradigm from 'race' to human genome variation. Nat Genet 2004;36:S5-7.

56. Parra EJ, Kittles RA, Shriver MD. Implications of correlations between skin color and genetic ancestry for biomedical research. Nat Genet 2004;36:S54-60

57. Nagashima N, Watanabe T, Nakamura M, Shalabi A, Burdick JF. Decreased effect of immunosuppression on immunocompetence in African--Americans after kidney and liver transplantation. Clin Transplant 2001;15:111-5.

58. Maggard M, Goss J, Ramdev S, Swenson K, Busuttil RW. Incidence of acute rejection in African-American liver transplant recipients. Transplant Proc 1998;30:1492-4.

59. Gaynor JJ, Moon JI, Kato T, Nishida S, Selvaggi G, Levi DM, Island ER, Pyrsopoulos N, Weppler D, Ganz S, Ruiz P, Tzakis AG. A causespecific hazard rate analysis of prognostic factors among 877 adults who received primary orthotopic liver transplantation. Transplantation 2007;84:155-65.

60. Velidedeoglu E, Mange KC, Frank A, Abt P, Desai NM, Markmann JW, Reddy R, Markmann JF. Factors differentially correlated with the outcome of liver transplantation in hev+ and HCV- recipients. Transplantation 2004;77:1834-42. 